Britta Patermann MD

University of Cologne, Cologne, Germany

E-mail: bpatermann@web.de

\section{Vital capacity and patient-controlled sevoflurane induction}

To the Editor:

We read with interest the article by Yogendran et al. ${ }^{1}$ comparing patient controlled inhalation induction (PCI) with the most commonly used vital capacity induction (VCI). The authors concluded that "PCI was comparable to VCI in sevoflurane induction with respect to the speed of induction, side effects during induction and patient satisfaction".

We partially disagree with this conclusion because we believe that there was a problem with the VCI in the study. Considering that the volume of gas inhaled in a vital capacity inspiration is $70 \mathrm{~mL} \cdot \mathrm{kg}^{-1}(5.6 \mathrm{~L}$ for an 80 -kg patient) and requires a very high peak flow that current vaporizers cannot accommodate, and considering that the authors used a circle breathing system connected to a Datex-Ohmeda ${ }^{\circledR}$ AS/3 unit with a canister volume of $900 \mathrm{~mL}$ and a 2 -L reservoir (information obtained from authors), and assuming the average patient's weight is $80 \mathrm{~kg}$, the primed circuit afforded half of the volume needed for a VCI induction. Consequently, patients in the VCI group didn't breath sevoflurane 6 to $8 \%$, but instead received diluted sevoflurane 3 to $4 \%$ during the first minute of induction. This might explain the 1.5 -min necessary to achieve loss of eyelash reflex in the VCI group in the present study, in contrast to the induction times (32 to $54 \mathrm{sec}$ ) generally reported by other authors, ${ }^{2-4}$ even without $\mathrm{N}_{2} \mathrm{O} .{ }^{5}$ Five-litre reservoir bags should be used, and fresh gas flow can be reduced to $2 \mathrm{~L} \cdot \mathrm{min}^{-1}$ after loss of conciousness to diminish sevoflurane consumption in VCI.

Marie-José Colas MD FRCPC

René Martin MD FRCP

Centre Hospitalier Universitaire de Sherbrooke, Sherbrooke, Canada

E-mail: rene.martin@USherbrooke.ca

\section{References}

1 Yogendran S, Prabhu A, Henly A, et al. Vital capacity and patient controlled sevoflurane inhalation result in similar induction characteristics. Can J Anesth 2005; 52: 45-9.

2 Yurino $M$, Kimura $H$. A comparison of vital capacity breath and tidal breathing techniques for induction of anaesthesia with high sevoflurane concentrations in nitrous oxide and oxygen. Anaesthesia 1995; 50: 308-11.

3 Yurino $M$, Kimura $H$. Induction of anesthesia with sevoflurane, nitrous oxide, and oxygen: a comparison of spontaneous ventilation and vital capacity rapid inhalation induction (VCRII) techniques. Anesth Analg 1993; 76: 598-601.

4 Colas MJ, Tétrault JP, Dumais L, Truong P, Claprood $\Upsilon$, Martin $R$. The SiBI connector: a new medical device to facilitate preoxygenation and reduce waste anesthetic gases during inhaled induction with sevoflurane. Anesth Analg 2000; 91: 1555-9.

5 Yurino $M$, Kimura $H$. Comparaison of induction time and characteristics between sevoflurane and sevoflurane/nitrous oxide. Acta Anaesthesiol Scand 1995; 39: 356-8

\section{Intubating conditions associated with the Mallampati "class zero" airway}

To the Editor:

The recent correspondence by Sakuragi et al. describing tracheal intubation in an adult male with a Mallampati class zero airway was of interest to us. ${ }^{1}$ Although it was correctly identified that Ezri et al. failed to identify any adult men with a Mallampati class zero airway in a series of 764 patients, ${ }^{2}$ two such cases have been reported previously. 3,4

We, too, have encountered patients with a class zero airway. The first patient was a 48-yr-old male whose epiglottis was visible on mouth opening and tongue protrusion. Ventilation was easily managed following induction of general anesthesia. Cormack and Lehane laryngoscopy was grade 1 , and he was easily intubated. ${ }^{3}$ However, the experience from a limited number of cases does not imply that a Mallampati class zero airway will predict easy intubation, as suggested by Sakuragi et al. ${ }^{1}$ We have also reported a difficult grade 3 laryngoscopy in a 52 -yr-female with Mallampati class zero airway, due to a large obstructive epiglottis. ${ }^{5}$ However, we did not encounter difficulty in mask ventilation in this patient. In contrast, in a 69-yr-old male patient with a Mallampati class zero airway, Fang and Norris reported extreme difficulty in mask ventilation, in addition to difficult intubation with a laryngoscopic view grade $3 .{ }^{4}$ It is possible that a large redundant epiglottis acts as a flap, blocking the glottic opening every time positive pressure is applied to ventilate the patient. Further, a large epiglottis may 
overhang the tongue as seen on preoperative airway examination, and restrict the view of laryngeal inlet once the patient is paralyzed under anesthesia. ${ }^{5}$

At present, we observe that patients with a class zero airway may belong to any age group. We have undertaken a study to determine the incidence of Mallampati class zero airway, and its possible correlation with age, sex, body mass index, and other factors. ${ }^{5}$ Until the results of this trial are available, we suggest that all patients with class zero airway should be subject to indirect laryngoscopy to check whether the epiglottis hinders the laryngoscopic view. Furthermore, the ability to ventilate such patients with a facemask must be confirmed before administration of a neuromuscular blocking drug. ${ }^{3,5}$ In conclusion, we disagree with Sakuragi et al. that a class zero airway should necessarily predict easy tracheal intubation, and that one should, in fact, be prepared with the "difficult intubation drill" when presented with such a patient.

Rajesh Mahajan MD

Vinod Kumar Grover MD MNAMS

Post Graduate Intstitute of Medical

Education and Research, Chandigarh, India

E-mail: drmahajanr@rediffmail.com

\section{References}

1 Sakuragi T, Hori K, Shiratake T, Miyawaki J, Ishida $M$. Tracheal intubation in a adult male with Mallampati class zero airway. Can J Anesth 2005; 52: 115-6.

2 Ezri T, Warters RD, Szmuk P, et al. The incidence of class zero airway and the impact of Mallampati score, age, sex, and body mass index on prediction of laryngoscopy grade. Anesth Analg 2001; 93: 1073-5.

3 Grover VK, Mahajan R. Class zero airway and laryngoscopy. Anesth Analg 2004; 98: 870-1.

4 Fang B, Norris J. Class zero airway and laryngoscopy. Anesth Analg 2004; 98: 870-1.

5 Grover VK, Mahajan R, Tomer M. Class zero airway and laryngoscopy. Anesth Analg 2003; 96: 911.

\section{Head computed tomography scan fol- lowing cardiac arrest}

To the Editor:

The recent recommendations for patient care following cardiac arrest ${ }^{1}$ provide a useful, evidence-based approach to the management of this group of patients. However, some of the recommendations, especially those based on lower grades of evidence, probably need further debate.
The authors suggest that routine computed tomography (CT) of the head is not indicated (grade E evidence). We would argue that CT of the head is indicated in patients who remain unconscious following a cardiac arrest, especially those who are being considered for therapeutic hypothermia.

Kurkciyan and colleagues found that spontaneous subarachnoid hemorrhage ( $\mathrm{SAH})$ was the immediate cause of $4 \%$ of community cardiac arrests. ${ }^{2}$ The majority of these patients had no prodromal symptoms to suggest an intracerebral event.

Therapeutic hypothermia may not be appropriate in patients who have suffered a SAH. There is no evidence of benefit of therapeutic hypothermia in this group of patients, ${ }^{3}$ and it is possible that $24 \mathrm{hr}$ of therapeutic hypothermia followed by rewarming would lead to a delay in both the diagnosis of SAH and appropriate surgical intervention. Cooling to $32^{\circ} \mathrm{C}$ may cause a coagulopathy as a result of impaired enzyme activity and platelet function, which may be detrimental to patients with $\mathrm{SAH} .{ }^{4}$

Joellene R. Mitchell FRCA

Paul Jefferson FRCA

David R. Ball MB BS

Dumfries and Galloway Royal Infirmary, Dumfries, UK

E-mail: jmitchell2@nhs.net

\section{References}

1 Bell DD, Brindley PG, Forrest D, Al Muslim O, Zygun $D$. Management following resuscitation from cardiac arrest: recommendations from the 2003 Rocky Mountain Critical Care Conference. Can J Anesth 2005; 52: 309-22.

2 Kurkciyan I, Meron G, Sterz F, et al. Spontaneous subarachnoid haemorrhage as a cause of out-of-hospital cardiac arrest. Resuscitation 2001; 51: 27-32.

3 Inamasu J, Ichikizaki K. Mild hypothermia in neurologic emergency: an update. Ann Emerg Med 2002; 40: 220-30.

4 Wolberg AS, Meng ZH, Monroe DM 3rd, Hoffman M. A systematic evaluation of the effect of temperature on coagulation enzyme activity and platelet function. J Trauma 2004; 56: 1221-8.

Reply:

We appreciate the positive comment of Mitchell et al. regarding our recommendations for management of patients resuscitated from cardiac arrest. Unfortunately, many recommendations are based on low grade evidence, and we agree further debate and investigation are required. Mitchell et al. cite a $4 \%$ reported incidence of 